Vladislava Gordić Petković

\title{
SVE LEKCIJE STAKLENOG ZVONA
}

Jedini roman pesnikinje Silvije Plat, Stakleno zvono (The Bell Jar, 1963) često se nepravedno svodi na stilizovanu ispovest zato što su u njemu verno predstavljeni apatija i dezorijentisanost koji autorku odvode u pokušaj samoubistva, pa potom do psihijatrijske klinike i dugotrajne terapije. Platova je, slično Hemingveju, znala da iskustvo zahteva preradu i stilizaciju kako bi postalo umetnost, pa tako narativna struktura zasnovana na fragmentarnoj retrospektivi i svedenoj karakterizaciji junaka, presudno razlikuje ovaj roman od autobiografije. Klinička slika zdravstvene i identitetske krize Silvije Plat dobrim delom je i slika krize životnog izbora koja se stavlja pred ženu pedesetih godina prošlog veka.

Ključne reči: Silvija Plat, roman, autobiografija.

U okvirima moderne književnosti, Silvija Plat važi za, uvek redak, primer „školovanog talenta”, koji uspeva da i na temeljima nesigurnim kao što su narušeno mentalno zdravlje i psihičko rastrojstvo izgradi autentično umetničko delo. U njenoj poeziji su pažljivo i efektno sučeljeni histerija i egzaltiranost, liričnost i žestina, eruptivne emocije i brižljivo oblikovane metafore. Silvija Plat je ključna figura takozvane konfesionalne poezije, koju odlikuju otvorenost i neposrednost u obradi tema „privatnog pakla”, ali isto tako i kroz figurativan jezik kanalisana jezovita strast za samouništenjem.

Pesme Silvije Plat odlikuje surova otvorenost i otvorena surovost koje prozivaju i povređuju; u čvrstom uverenju da ni najstrašnije lično iskustvo ne sme da utone u sopstvenom odrazu, pesnikinja sebe dramatizuje u mnogo neobičnih, čak šokantnih uloga: sebe vidi kao žrtvu masovnih zločina, kao odraz mitoloških i biblijskih junaka i junakinja (kao Elektru ili pak žensku verziju vaskrslog Lazara), dok su domi- 
nantne muške figure predstavljane u ulogama spasitelja ili izdajnika, čak i nacističkog mučitelja, a u jednoj od pesama otac se pojavljuje metaforično - kao tesna crna cipela. Sa druge strane, njenoj poeziji ne nedostaju idilične i prijatne teme, slike iz prirode i motivi majčinstva, diktirani neposrednim emotivnim iskustvima.

Kratki, intenzivni stvaralački put Silvije Plat vodi kroz istorijsko i kulturno razdoblje u kom još uvek nema jasno definisane formalne rodne ravnopravnosti, kroz vreme u kom se ženskom autorstvu otvara neuporedivo manje mogućnosti nego što ih imaju muškarci pisci i u kom su ženske i muške uloge i perspektive unapred striktno raspoređene. Na političkom planu, to je vreme Hladnog rata, zastrašivanja i represije, dominacije senatora Džozefa Makartija i njegovog opsesivnog i opasnog progona simpatizera komunističke ideologije, vreme u kome vladaju strah, nesigurnost i kompulzivna potreba za pojačanom kontrolom. Možda je paradoksalno što se baš u ovakvom istorijskom razdoblju u poeziji kristališe ispovedni manir, podstican koliko i obeshrabrivan. Ranije nezamisliva spremnost da se eksponiraju i analiziraju zatomljivani emotivni problemi i traume manifestuje se krajem pedesetih i početkom šezdesetih godina prošlog stoleća između ostalog i kao mogućnost da se otvoreno progovori o depresiji, neurozama i svim oblicima psihičke labilnosti koje se automatski pripisuju ženama. Snažan prodor u lično emotivno iskustvo, govor o mentalnom zdravlju, psihičkoj nestabilnosti, krizama i mračnim trenucima biće obeležje poezije i drugih američkih pesnika, Roberta Louela i En Sekston, da pomenemo samo one sa kojima je Silvija Plat bila bliska i poetički i privatno.

Ženski likovi se u književnosti različitih epoha često grade na osnovama stereotipa o zadatim rodnim ulogama, a ženama stvaraocima olako se pristupa iz predubeđenja da njihov rad vodi nekakva specifično ženska imaginacija, ili pak s idejom da njihovim postupcima upravlja imaginarna, jednom za svagda „Zadata” ženska priroda koja je univerzalna, jednoznačna i nepromenljiva. Zato je važno, kada se o Silviji Plat govori, da se njena tragična sudbina i njena rastrzanost između snažne ambicije i jednako snažnog osećanja nemoći sagledaju kao neponovljive i unikatne, bitno određene rodnim ulogama ali 
ipak dominantno profilisane nesvodivom umetničkom samosvojnošću jednog izuzetno kompleksnog temperamenta. Ne postoji, dakle, nikakva unapred zadata slika ženskog - postoji samosvest koja se u određenom istorijskom trenutku artikuliše u književnoj formi. Možemo stoga Silviju Plat posmatrati kao ikonu feminizma, kao Galateju koju je Pigmalion prvo uzvisio pa potom izneverio; možemo je opisati kao Persefonu koja pola vremena provodi na svetlu dana, u radostima svakodnevice, a pola u tami podzemnog sveta depresije i autodestrukcije, možemo i naglašavati kako stvaralačku ekspanziju delom duguje i svom tamničaru i zlodejniku, svom suprugu, engleskom pesniku Tedu Hjuzu. Pesnički bračni par ovakvim je slikama mitologizovan do apsurda: jedna kritičarka je Hjuza, tako, cinično opisala kao najozloglašenijeg supružnika u istoriji nakon Ksantipe. Stavljanje lika i dela Silvije Plat u ram za sliku muža tiranina čija izdaja poverenja odvodi u samoubistvo predstavlja pokušaj da se njen autentični talenat marginalizuje.

I paradoksalno i utešno može zvučati teza da je duševni poremećaj u isti mah i problem, i rešenje problema: nastala usled pritisaka koji dolaze spolja, mentalna bolest je način da se ti pritisci izdrže. Odnos bolesti i stvaranja je složen, i ne manifestuje se na očekivani ili uniformni način. Predubeđenja o neliterarnim uticajima ne uspevaju da zasene delo Silvije Plat niti da ga uproste ili banalizuju, iako su biografska tumačenja njenog opusa i dalje vrlo uporna: štaviše, sve su zaoštrenija, uprkos tridesetogodišnjem ćutanju njenog supruga, koje je prekinuto tek ispovednom zbirkom pesama Rodendanska pisma.

Jedini roman Silvije Plat, Stakleno zvono, često se nepravedno svodi na stilizovanu ispovest o letu 1953, kad su se ukrstile snažna ambicija i jednako snažan osećaj nesigurnosti i kad je mračni podzemni svet njenih opsesija i strahova umalo odneo pobedu nad svetlošću stvaranja. Tačno je da su izuzetno verno predstavljeni apatija i osećaj izgubljenosti koji pesnikinju odvode u pokušaj samoubistva, pa potom do psihijatrijske klinike i terapije elektrošokovima; međutim, Platova je, slično Hemingveju, znala da iskustvo zahteva preradu i stilizaciju kako bi postalo umetnost. Struktura romana, zasnovana na paralelnim tokovima pripovedanja, fragmentarnoj retrospektivi i 
upečatljivoj, iako svedenoj, karakterizaciji junaka, presudno ga udaljuje od autobiografije. Glavna junakinja Ester Grinvud pripoveda reporterski mirno, staloženo i objektivno (čak i automatski, čini se na trenutke) iako je jasno da njena distanca od traumatičnih dogadaja ne može biti velika. Klinička slika njene zdravstvene i identitetske krize dobrim delom je i slika krize životnog izbora koja se stavlja pred ženu pedesetih godina prošlog veka. Psihička bolest je Esterina reakcija na svet oko nje koji, tražeći prilagodljivost unapred određenim okvirima, traži previše - programiranost i predvidljivost, poslušnost i prepuštanje kolotečini. Motiv staklenog zvona je, otud, i označitelj sputavajuće kulture pedesetih (Boyer 2014: 201), i simbol konstantnog osećaja gušenja i zatočeništva, osećaja koji se stalno preispituje jer se iza staklenih zidova sve vreme vidi taj drugi, navodno idilični, nominalno „zdravi” svet tihe većine, uronjen u sve one rutine koje su zatočenici neshvatljive i nepodnošljive. Iako kritika socijalnog okruženja i svest o kontekstima rodne neravnopravnosti u kojima se razvijaju i Esterina bolest i njen talenat ne bi smeli da zamagle istoriju bolesti, Stakleno zvono može da se čita kao gorka alegorija o mentalnoj nestabilnosti koja je mnogo veća prepreka ostvarenju ambicija nego socijalni pritisci, jer je ponovo stečeni, naknadno uspostavljeni psihološki sklad uvek tako loman i varljiv.

Leto 1953. opisano u Staklenom zvonu ključni je formativni period u životu Silvije Plat, idiličan pa traumatičan; u pitanju je nekoliko nedelja uspeha i počasti, nakon kojih sledi šest mračnih meseci teške psihičke krize i sporog oporavka. Nakon juna koji je u Njujorku provela kao stipendistkinja časopisa Madmoazel i jedna od dvanaest strogo selektovanih gostujućih urednica, perioda koji naziva talasom svog kreativnog i društvenog uspeha, Silvija Plat pada u depresiju; nesanica, bezvoljnost i poremećaji u ponašanju odvode je u psihijatrijsku bolnicu, gde biva podvrgnuta elektrošokovima. Sledi izuzetno težak period prepun očajanja i slabosti; pokušala je samoubistvo 24. avgusta i nakon toga se lečila i oporavljala u bolnici u Belmontu, u Masačusetsu, gde je dobijala insulinsku terapiju i elektrošokove.

Silvija Plat je Stakleno zvono počela da piše 1961, pošto je objavljena njena pesnička zbirka Kolos, a dovršila ga je pošto se rastala od 
Teda Hjuza, bezmalo u dahu i bez puno naknadnih korekcija rukopisa. U pitanju je odista redak primer autobiografski motivisanog romana $\mathrm{u}$ kom jasnu proznu strukturu prati metaforičan jezik koji je istovremeno poetičan, potresan i reporterski objektivan. Uglavnom se posmatra kao „roman s ključem” zato što naracija prati razvoj, tok i lečenje kliničke depresije glavne junakinje Ester Grinvud, proces duševne bolesti koji je paralelan sazrevanju i junakinje i autorke. Međutim, daleko od toga da je roman pisan iz potrebe za samopročišćenjem: Silvija Plat bolna iskustva psihičkih kriza, pokušaja samoubistva i bolničkog lečenja eksternalizuje, udaljava se od njih, uspevajući da mračne teme samoranjavanja i spoznaje fizičkog bola i slabosti predstavi kao deo rituala ili igre, otkrivajući, sa druge strane, koliko prividno lagodan život i rutinski postupci svakodnevice mogu biti naporni i razorni po osetljivu dušu i labilnu prirodu.

Roman je u januaru 1963. objavljen u Velikoj Britaniji, u izdanju Vilijam Hajneman Limitida, pod pseudonimom Viktorija Lukas, iz više razloga: $\mathrm{s}$ jedne strane, Silvija Plat nije bila sigurna u to da je napisala ono što bi sama smatrala „ozbiljnim delom”; potreba da svoje pesničko ime udalji od proze diktirana je i brigom da ne nanese duševni bol majci, školskim drugaricama i poznanicima koji figuriraju u Staklenom zvonu, tek ovlaš maskirani, neznatno zamagljeni, počesto i karikirani. Stakleno zvono je prvi put objavljeno pod pravim imenom autorke godine 1967, a u Sjedinjenim Američkim Državama premijeru doživljava četiri godine docnije, u skladu sa željama Silvijine majke i supruga.

Roman je izdavač Harper and Rou odbio kao mladalačko delo koje ne ispunjava postavljena očekivanja, a put do objavljivanja trajao je mnogo duže u Americi nego u Evropi, jer su američki urednici smatrali da roman ne uspeva dovoljno dobro da inkorporira građu. Iz pisma koje je Aurelija Plat poslala uredniku u izdavačkoj kući Harper and Rou nazire se mogućnost da Stakleno zvono dobije nastavak. Prisećajući se razgovora koji je vodila sa ćerkom u julu 1962, Aurelija pominje Silvijine reči kojima opisuje roman: „pokušala sam da predstavim svoj svet i ljude u njemu viđene kroz izmenjenu perspektivu staklenog zvona”. Najavila je i da će njena naredna prozna knjiga „isti 
taj svet predstaviti viđen očima zdravlja” (BOYER 2004: 202); ona, medutim, nikada nije napisana.

Tema romana je razvoj i rast glavne junakinje, obeležen mentalnim sunovratom koji će uslediti nakon niza razočaranja u sebe i u svet. Komponovan kao niz naknadnih sećanja u kojima se ukazuju delići prošlosti glavne junakinje Ester Grinvud, roman najviše govori o potrebi socijalne integracije, koja je nemoguća, ili barem nepotpuna, pre nego što junakinja shvati ko jeste, i šta želi da bude. Tema Staklenog zvona je, ništa manje, borba protiv autoriteta i zadatih normi: Ester se na otvoren ili uvijen način sukobljava sa pretpostavljenima i autoritetima, sa emotivnim partnerima, majkom i lekarima. Potreba da se kreira društveno prihvatljiv identitet najčešće se okončava pretvaranjem u ono što bi od nas želeli da načine drugi, te tako i Ester rizikuje da samu sebe izgubi zbog potrebe da se prilagođava svemu što njen mladić, tradicionalno odgojeni, samozadovoljni i samoživi Badi Vilard očekuje od nje. Potreba za ženskom emancipacijom izražava se i jasno i simbolički, metaforama izbora koji su pred junakinjom, ali sam čin izbora ne znači da je i ostvarenje želje nadohvat ruke. U želji da postane sve o čemu sanja, Ester je, kao i svaki neurotičar, istovremeno opsesivna i kolebljiva. Koliko god bile snažne njene ambicije, inhibicije su jače, te je ostvarenje njenih težnji i strasti redovno osujećeno, bilo nimalo zanemarljivim ograničenjima konzervativne Amerike pedesetih, bilo unutrašnjim porivom za destrukcijom, koji sve vreme sabotira otvoreno iskazivanu volju i ambiciju.

Nije čudno, otud, što je Esterin odnos prema svetu i budućnosti, željama i planovima, tako naglašeno predstavljen njenim odnosom prema hrani: lavirajući između bulimijskog prejedanja i povraćanja s jedne strane i izgladnjivanja u periodu psihoterapije sa druge, Ester simbolički iskazuje isprva tih, a potom buran protest protiv nametnute ideje o ulozi žene u društvu u kojoj se stiču protivrečni i nemogući zahtevi. Prejedanje je Esterin pokušaj da nahrani svoju ambiciju, koja bi u njenoj okolini bila dobrodošla samo ako podrazumeva pretvaranje žene u savršenu domaćicu. Ester želi da balansira između više uloga, da osvoji pravo na to da bude bez ikakvih planova za budućnost, što je donekle u suprotnosti sa Silvijom Plat koja je sebe strasno, 
dugo i uporno pripremala za pesnički poziv, koliko god joj ni drugačiji izazovi, izazovi da se prepusti čarima novinarstva, akademske karijere ili uredničkog posla ne bili strani. Esterin život postepeno postaje sušta suprotnost društvenim zahtevima i reklamnim oglasima pedesetih, koji ženama svestranost i savršenstvo istovremeno obećavaju i nalažu, a potom nastupa potpuni slom. Dok prvi deo romana govori o Esterinim potrošačkim impulsima koji su u dobroj meri bulimijski (prejedanje, impulsivno i kompulsivno kupovanje odeće i obuće, zgrtanje besplatnih poklona), drugi opisuje njenu laganu dezintegraciju, očajničku borbu da se iščupa iz staklenog zvona i simboličnu, makar i privremenu pobedu želje za životom.

Roman počinje jednom snažnom slikom smrti koja je u vreme Silvijinog boravka u Njujorku bila vest dana: najavljeno pogubljenje bračnog para Rozenberg, osuđenog na smrtnu kaznu zbog špijunaže, kod Ester, uznemirene zato što ima utisak da je novinski naslovi gledaju sa svakog ugla, osvešćuje duboko potiskivani izazov autodestrukcije. Optuženi da su ruski špijuni koji su nuklearne tajne SAD prodavali Sovjetskom Savezu, Džulijus i Etel Rozenberg pogubljeni su u junu 1953. Medijsko prisustvo prokaženog bračnog para (čija je krivica dokazivana putem „zakonskog linča”, kako je sudski proces protiv njih nazvao Žan-Pol Sartr) u Ester izaziva samo misli o smrti i uništenju, iako je došla u Njujork sa pompom i počastima, kao gostujuća urednica u časopisu Madmoazel, iako uživa u večerama, koktelima, besplatnim poklonima. Rozenbergovi su otpadnici, žigosani, antiheroji, a i sama Ester se, kako roman odmiče, sve više tako oseća. Simbolika njihovog stradanja jeste i simbolika dokazane krivice: Ester tone u depresiju, vođena samooptuživanjem i osećanjem manjkavosti. S druge strane, pogubljenje bračnog para samo je prvi simbolički nagoveštaj da će Njujork biti gubilište na mnogo načina, mesto gde umiru ambicije i iluzije podjednako. Letnji program za koji je bila izabrana Silvija Plat pokrenut je 1939, sa dvostrukom namerom: oglašivači su u procesu rada sa pažljivo izabranim stipendistkinjama dobijali dragocene podatke o željama i očekivanjima elitnog dela tržišta a mlade, još uvek neafirmisane autorke dobijale su priliku da pokažu svoja znanja i talente, da naprave prvi korak na nečemu što bi moglo biti uspešna 
karijera. Među učesnicama programa bile su svojevremeno i poznate američke prozaistkinje Džoan Didion i En Biti, kao i glumica Ali Mekgrou. Leto u Njujorku za Ester je svojevrsni silazak u podzemni svet: upoznajući i sebe i svet u novim situacijama i novim kontekstima, junakinja se suočava sa krhkošću svoje motivacije i čeličnim stegama socijalnih normi. Umesto da grad bude obećanje smisla, centar novih iskustava i saznanja, u njemu se ređaju emotivna, seksualna i profesionalna razočaranja.

Kako vreme prolazi, delo Silvije Plat sve se više sagledava iz ugla književne tradicije i socijalnog poretka pedesetih i šezdesetih godina prošlog veka. Potreba da se njena biografija romantizuje, a uloga njenog supruga Teda Hjuza demonizuje, sledila je nekakvu zacrtanu senzacionalističku glad koja se iz književnog biografizma preselila u celuloidne trivijalizacije. Ipak, važno je reći da je sama Silvija Plat razmišljala o komercijalizaciji sopstvenog iskustva, a da je čak Stakleno zvono nazivala „petparačkim štivom” (potboiler): svesna medijske i čitalačke ljubopitljivosti u pogledu tema privatnog pakla, u dnevnicima konstatuje kako postoji rastuće tržište koje je zainteresovano za teme mentalnih bolnica i da je „budala” ako to iskustvo ponovo ne proživi i ponovo ga ne stvori. Kreativna blokada koja ju je u obračunavanju sa temom psihičkog poremećaja dugo pratila nestala je nakon što je zbirka Kolos našla izdavača. To što je iste one 1953. odbijena za kurs kratke priče velikog teoretičara i kritičara Frenka O'Konora koji se održavao na Harvardu, bio je podsticaj da se i u Esterinom životopisu to iskustvo predstavi kao prelomno. No, Ester ponavlja još štošta iz života autorke: pokušaj samoubistva predoziranjem tabletama za spavanje, višednevna potraga koju su pratili napisi u medijima i pismo majci detalji su svi verno preuzeti iz Silvijinog života, ali brižljivo inkorporirani u fiktivni tekst.

Stakleno zvono bavi se temama sazrevanja i krize odrastanja, krizama rodnih uloga i odgovornostima koje je teško ili nemoguće prihvatiti. Ester je stešnjena između uzora koje ne želi da sledi i ambicija koje su teško ostvarive, između želje da piše i želje da živi, opsesije izbora i nesposobnosti da izabere. Uverena da je Stakleno zvono savremeni roman koji je u najvećoj meri pogrešno shvaćen, kritičarka 
Linda Vagner smatra da je ovo delo roman odrastanja i obrazovanja: sva iskustva Ester Grinvud doprinose njenom razvoju i sazrevanju, i ma koliko se junakinja činila rasuta i nezasita u nadanjima i željama, svaki opisani dogadaj vodi samootkrivanju i odrastanju, formiranju njenih etičkih stavova i građenju odnosa prema ljubavi i radu, bližnjima i okolini. Struktura romana je epizodična, i svi junaci sem Ester su fragmentarni i funkcionalni, prisutni samo onoliko koliko je potrebno da se oslika njen lik. Ta fragmentarnost nije mana: Ester sazreva na težak i traumatičan način, a njen zadatak nije da pronađe svoj identitet, već da ga izgradi. Ona mora da se odluči šta da bude; uloge koje joj se nude ne obećavaju potpunost i harmoniju, nijedna od njih sama za sebe nije dovoljna, a uzajamno se osporavaju i poriču. Ester ne može istovremeno biti nestašna i neodgovorna studentkinja koja manipuliše svojim profesorima, i renomirana, poštovana pesnikinja; uloga poslušne kćeri sukobljava se sa ulogom seksualne buntovnice; biti uzorna verenica Badija Vilarda koja strpljivo i pokorno čeka da on prebrodi tuberkulozu i da u braku s njim dosegne duhovni sklad u kom će pisanje poezije postati suvišno, njoj je nemoguće i neizdržljivo - no, s druge strane, ženski modeli poslovnog uspeha u knjižarstvu i izdavaštvu koje vidi u Njujorku ne nude primamljivu alternativu domaćičkom bračnom životu. U vremenu pre drugog talasa feminizma, u posleratnoj grčevitoj potrebi da se kreira porodični sklad u kom će uloge biti raspoređene na jednom dogovoren a zauvek važeći način, ženska individualnost suočava se sa nepremostivim mentalitetskim preprekama, kao i sa nezadovoljavajućim izlaznim strategijama.

Stakleno zvono je roman o umetnici u nastanku: umetničkoj duši svet nikako nije dom, mnogo je bola i nesporazuma potrebno iskusiti i prevazići da bi se individualni talenat u sudaru sa tradicijom kreativno realizovao. Stakleno zvono je roman o borbi za sopstvenu dušu, za duševno zdravlje i za duševni mir, koliko i za etičku ravnotežu: depresivna i agresivna junakinja menja fokus i raspoloženja, pristaje na konflikte, laži i zlostavljanje nesvesna da pogrešno usmerava energiju, da traži krivce gde ih nema a sreću gde je ne može biti. Stakleno zvono je roman o posebno „složenom slučaju” odrastanja u kom sazrevanje može da se dogodi tek nakon sloma: o pobuni i revoltu koji se završa- 
vaju u ludnici, ali i izvedu iz nje. Sama metafora staklenog zvona ukazuje na gušenje, sapetost, zatvor u kom nema vazduha, mesto u kome nema izbora ni alternative, samo čekanje na laganu smrt.

Početna čitalačka recepcija romana bila je, po osećaju autorke, prilično mlaka: kritički sudovi koji su ukazivali na dobar stil i lošu strukturu dela nisu baš delovali podsticajno na nekog ko se čupa iz bezdana. Ponešto izrečenog danas ipak zvuči makar kao prepoznavanje autorske intencije ako već ne i kao kompliment: u časopisu Nju Stejtsmen Robert Taubman je Stalkeno zvono nazvao „prvim ženskim romanom u Selindžerovom ključu” (Taubman 1963: 128). Deo kritičarskih nesporazuma sa ovim delom - za Sola Malofa je ono „više zabeleženo nego zamišljeno" (MALOFF 1971: 33) - opravdava i zbunjenost pred činjenicom da je Stakleno zvono istovremeno povest ženskog odrastanja i studija mentalnog pomračenja. Roman sadrži i socijalnu, i ličnu priču kakvih na horizontu pedesetih nije bilo. Prvi kritičari koji su pisali o romanu najviše su se bavili kontekstom mesta i vremena, ukazivali na satirične elemente u predstavljanju Esterinog života u Njujorku, iscrpljivali se u poređenju konvencija i normi romana i biografije, u ispitivanju rezultata dodira biografske realnosti i estetskog iskustva. Zivot i sudbina autorke eksplicitno su korišćeni i da se napadnu i da se odbrane navodna slaba mesta u romanu i ono što je nazivano „nesvarenim autobiografizmom” (O'HARA 1971: 3).

Stakleno zvono je roman o ritualu dvostrukog rođenja, kako nam i sama junakinja jasno kaže: ono drugo, mračnije i važnije, okončava roman nedoumicom da li će se stakleno zvono ikada podići i dozvoliti Ester da utekne u željeni život - koji god to život bio. 


\section{IZVORI I CITIRANA LITERATURA}

Boyer, Marilyn. "The Disable Female Body as A Metaphor for Language in Sylvia Plath's The Bell Jar”. Women's Studies, XXXIII, 2004, 199-223.

Downdia, Renee. "Consuming Appetites: Food, Sex and Freedom in Sylvia Plath's The Bell Jar". Women's Studies, XLIII, 2014, 567-588.

Gordić Petković, Vladislava. "Constructing Gender Roles in Literature and Criticism: Elaine Showalter and Anglophone Women's Literary History". Filolog, V, 2014, 186-193.

Holmes, Janet, Miriam Meyerhoff. The Handbook of Language and Gender. Oxford: Blackwell Publishing, 2003.

Mailoff, Saul. "Waiting for the Voice to Crack". New Republic, CLXIV/19, 1971, 33-35.

Marot Kiš Danijela, Ivan Bujan. „Tijelo, identitet i diskurs ideologije”. Fluminensia XX/2, 2008, 109-123.

O'Hara, J. D. "An American Dream Girl". Washington Post Book World, 11. april 1971, 3.

Plath, Sylvia. The Bell Jar. New York: Bantam Books, 1971.

Taubman, Robert. "Antiheroes". The New Statesman, LXV/1663, 1963, 128.

Wagner, Linda. "Plath's The Bell Jar as Female Bildungsroman". Women's Studies, XII, 1986, 55-68.

Vladislava Gordić Petković

ALL THE LESSONS OF THE BELL JAR

Summary

The Plathian legacy cannot be fully understood or appreciated without a thorough analysis of Sylvia's only novel, The Bell Jar, published under the pseudonym of Victoria Lucas in 1963. The novel about the plight of a young woman in the fifties who tries to overcome the values of domesticity and pursue her artistic ambitions has been widely read and reread, but regretfully remained in focus mostly because of vivid biographical details woven into the plot. 
The hegemonic patriarchal system hurts both the body and the mind of Esther Greenwood in many ways, and her mental illness can be interpreted as a strategy of resistance which partly induces self-annihilation.

Keywords: Sylvia Plath, novel, autobiography.

Univerzitet u Novom Sadu

Filozofski fakultet

vladysg@yahoo.com 